\title{
Gossip as social control?: Informal sanctions on ethical violations in scientific workplaces
}

\begin{abstract}
Research on misconduct in science has largely focused on egregious violations such as fabrication, falsification, and plagiarism. Recent scholarship, however, calls for greater attention to forms of everyday misconduct and how scientists navigate ethical ambiguity when they are unable or unwilling to make formal accusations. Drawing on interview data from 251 physicists and biologists from both elite and non-elite universities and research institutes in the US, UK, and India, we find that scientists are often reticent or unable to take formal action against many behaviors they perceive as unethical and irresponsible. As a result, they resort to informal gossip to warn colleagues of transgressors. Many express confidence that such prosocial gossip can serve as a means of social control by tarnishing the reputations of transgressors. Yet its effectiveness as a form of social control is limited, particularly when transgressors enjoy higher status than gossipers. We identify two types and three consequences of such gossip and assess the effectiveness of gossip as a means of social control. Finally, we consider the implications of our study for understanding and decreasing misconduct in science.
\end{abstract}

Keywords: gossip, misconduct, science, scientists, ethics 
Research misconduct is a topic of growing concern in the scientific community. This concern cuts across scientific disciplines because of the threat that misconduct poses to public trust in science. The physics community, for instance, was shocked by the scandal of Jan Hendrik Schön, whose numerous claims of breakthroughs in molecular electronics, published in the top journals in the field, turned out to be fraudulent (Reich 2009). An equally famous example in the biological sciences is that of South Korean professor Hwang Woo Suk, a oncecelebrated stem cell researcher convicted of data fabrication related to the creation of human embryonic stem cells. This scandal posed a threat to funding for stem cell research altogether (Kakuk 2009). Increasing retractions in top scientific journals have prompted calls for urgent reform (Zimmer 2012). Indeed, many have even begun advocating for the criminalization of research misconduct because it constitutes a squandering of public resources. One recent study found that papers retracted due to misconduct cost the NIH approximately $\$ 58$ million in direct funding between 1992 and 2012 (Stern et al. 2014). In sum, ethical breaches in science are challenging the public's perception of the trustworthiness of science and the integrity of scientists, thus constituting an important social problem.

Existing research on science ethics is focused primarily on three types of misconductfabrication, falsification, and plagiarism in the research process (Bird 2006; Check 2002; Dawson 2003; Dooley and Kerch 2000). The focus on such forms of misconduct certainly helps limit excessive oversight and regulation, but ends up sanctioning only a handful of individuals every year, and neglects many forms of everyday misconduct that scientists themselves consider as undermining scientific integrity (De Vries, Anderson, and Martinson 2006). As a result, scholars of science ethics have started to emphasize the need to pay attention to a broader range of forms of irresponsible conduct in day-to-day scientific practice. These include behaviors such 
as exploiting students, misusing research funds, careless or "sloppy" research practices, stealing ideas from colleagues, withholding details of results in papers, sabotaging colleagues, and inadequate record keeping related to research projects (Anderson et al. 2007). Attending to such behaviors takes more seriously the concerns voiced by scientists themselves about challenges and compromises to scientific integrity (De Vries, Anderson, and Martinson 2006). Such practices violate widely held scientific norms of communalism, disinterestedness, and originality (Merton 1973a; Ziman 2000), and may also foster institutional environments that are conducive to more serious ethical violation (Anderson, Louis, and Earle 1994). While scientific institutions in most countries have policies and procedures in place to deal with these relatively clear cut forms of misconduct, how do scientists negotiate these more ordinary forms of misconduct that they come across on a more frequent basis? Our in-depth interviews with 251 physicists and biologists in the US, UK, and India reveal one common practice for negotiating seemingly ordinary forms of misconduct is gossip.

A researcher's reputation in the scientific community is crucial for one's career. Most scientific research today depends on collaboration, and one cannot successfully collaborate with others, win grant funding or hope to be taken seriously without a solid reputation. If other scientists engage in gossip about unethical or irresponsible behaviors on the part of perceived transgressors, it could seriously undermine their reputations in the scientific community—and by extension, their scientific careers. Therefore, gossip is potentially an important mechanism of social control.

By engaging in gossip, scientists warn colleagues about transgressors, tarnishing the latters' reputation in an effort to minimize their potential to cause future damage. It can thus be seen as a form of "prosocial gossip" (Feinberg et al. 2012). In this article we examine scientists' 
perceptions of gossip as a mechanism of social control. We find that scientists emphasize the centrality of a good reputation to one's scientific career. Many believe that gossip, because of its ability to compromise scientists' reputations, is an effective means of informal policing or social control that can deter unethical behaviors that could jeopardize one's standing and success in science. Indeed, the fear of gossip and of a tarnished reputation that was pervasive among our respondents suggests that gossip may serve a pro-social role in deterring unethical behavior. But our interviews also suggest that such gossip is not always an effective means of social control. Gossip may be punitive but not corrective - transgressors may not know that they have become the subject of gossip or may not see the negative outgrowth of gossip as a consequence of misconduct on their part. ${ }^{1}$ Inaccurate or false gossip, disguised as concerned warnings, can unduly harm the reputations and careers of scientists. Reputational concerns can even inhibit scientists from informally challenging transgressors. Finally, even scientists who express confidence in the self-policing capacities of the field admit that transgressors with established status, networks, and reputations, remain successful in spite of negative gossip. Our findings, therefore, uncover a number of paradoxes about gossip in within science, and enable us to assess its effectiveness as a means of social control.

\section{$<\mathrm{A}>$ Ethically questionable behavior in science}

Reports of misconduct among scientists—“fabrication, falsification, or plagiarism in proposing, performing, or reviewing research, or in reporting research results" (ORI 2011) —are relatively rare. A recent meta-analysis of survey research suggests that only two percent of scientists say they have fabricated, falsified, or modified data at least once (Fanelli 2009). This same study, however, reports that nearly one-third admit to committing other less serious ethically questionable practices. These reports are likely on the conservative side, since social 
desirability might lead to an underreporting of deviant behavior in general. Thus, the problem (and the conditions that facilitate it) may be more widespread than we think.

Furthermore, the attention given to incidents of egregious misconduct in the media, and the scientific community, that tends to portray these few serious transgressors as anomalies-"a few bad apples"-undermines consideration of the importance of less blatant forms of unethical and irresponsible behavior. Recently scholars have begun to raise concerns about how the competitive, stressful, and politically fraught institutional context of science that have contributed to serious violations of ethical standards, might also be facilitating more subtle ways of jeopardizing the integrity of scientific research (Anderson, Louis, and Earle 1994; Anderson et al. 2007; Davis, Riske-Morris, and Diaz 2007; Freeman et al. 2001; Hackett 1994; Juliano 2003; Kennedy et al. 2004; Martinson, Anderson, and De Vries 2006; Teitelbaum 2003).

Scientists are largely aware of the rigorous policies and procedures that are in place to support allegations of serious misconduct such as falsification, fabrication, and plagiarism. For example, there are departmental, institutional, and organizational codes of ethics to consult, and evidence collected through the peer review and publication process to examine.

However, what do scientists do when they encounter instances of other ethically questionable behavior - what Raymond De Vries, Melissa S. Anderson, and Brian C. Martinson (2006) call "normal misbehavior" - that they are less willing, or less confident, to contest formally? What happens, for instance, when they suspect (but cannot prove) that the reviewer of a grant proposal they submitted stalled reviews in order to beat them to publication on a similar project? Or when they have colleagues in a position of power over them whose research they consider "sloppy," if not unethical, but whom they wouldn't dare confront? According to Gabriel (1995), one strategy that can be used in such situations of "unmanaged spaces" of organizations 
and social fields, where there is ambiguity about the violation (or how to respond to perceived violation) of collective norms is to circulate stories and evaluate discourses about perceived transgressors - in other words, gossip.

\section{$<\mathrm{A}>$ Gossip in professional contexts}

Gossip as a social phenomenon is a universal feature of human societies. As societies became larger and more complex, scholars argue that linguistic practices such as gossip enable group members to communicate information about reputations of members in order to assess trustworthiness, which serves to reduce selfishness and sustain group cohesion (Dunbar 2004). While the folk understanding of gossip is of informal talk that is usually considered a vice because of the slanderous and unverifiable nature of its contents, there is very little definitional consensus among scholars who study the phenomenon (Foster 2004; Noon and Delbridge 1993). Some highlight the function of gossip as protecting individual interests (Paine 1967); others see it as something people do for fun, in which case its value lies in the process rather than the outcome (Ben-Ze'ev 1994); and still others emphasize the evaluative nature of gossip (Foster 2004). (For an exhaustive list of definitions of gossip in the literature, see Michelson, van Iterson, and Waddington 2010:379). For our purposes here, we adopt a broad definition used in recent research (e.g., Feinberg et al. 2012; Foster 2004; Michelson, van Iterson, and Waddington 2010)_ _ evaluative talk between two or more persons about absent third parties.

Recent scholarship has started to pay attention to gossip in organizations, studying it as a phenomenon in its own right rather than as a byproduct of studies of organizational culture, conflict, or morale (Kurland and Pelled 2000; Noon and Delbridge 1993; van Iterson and Clegg 2008). This research has examined the role of gossip in transmitting information in ambiguous contexts (Rosnow 1977) and empowering marginalized members-for instance, by influencing 
reputations of managers (Ogasawara 1998). Sociological research on gossip has also examined the linguistic structure of gossip (Eder and Enke 1991) and how this varies depending on the institutional context (i.e., formal vs. informal) in which gossip takes place (Hallett, Harger, and Eder 2009). Our focus here is not on these linguistic and process-oriented factors, but on the consequences of gossip in scientific fields.

While gossip typically has negative connotations, Feinberg et al. (2012) argue that "prosocial gossip" has an important positive role in social life. What they mean by prosocial gossip is "the sharing of negative evaluative information about a target in a way that protects others from antisocial or exploitative behavior" (Feinberg et al. 2012: 1015). They argue that it contributes to social life by motivating members of a group to remain committed to group norms in the face of temptations of selfish action. Other research similarly points to the potential of gossip to reinforce social bonds and social norms (Kniffin and Wilson 2005; Noon and Delbridge 1993).

Academic science is an especially interesting field in which to study this form of gossip. Science is typically understood as being strongly communal, in its emphasis on collaboration as well as in allegiances to one's institution and sub-field. Yet, temptations to selfishness certainly abound among scientists, who inhabit a competitive environment in which there are incentives to put their individual selves or research groups ahead of the good of the community-for instance, racing to publish a new idea first in order to get credit, fame, and grant funding. Previous research has indicated that such competitiveness generates a number of perverse effects, including the withholding of data or results, delaying publication, secrecy among colleagues, exploitation of students, interference in the peer-review process, sabotage of colleagues' work, and retaliation for whistleblowing (Anderson et al. 2007; Blumenthal et al. 2006). These 
practices run counter to established scientific norms, such as communalism (the ideal that scientific knowledge must be shared transparently with the community), disinterestedness (the ideal that science should be motivated by the advancement of knowledge rather than by the pursuit of fame or money), universalism (the ideal that rewards such as positions and awards should be allocated based on purely scientific merit), and originality (the ideal that published scientific claims should make new and original contributions) (Merton 1973b; Ziman 2000). Such irresponsible practices can also entail violations of relational norms, particularly between faculty and students. Braxton, Proper, and Bayer (2011) catalogue here a number of "inviolable" norms (e.g., misappropriating students' work, or suppressing or punishing whistleblowers) and "admonitory" norms (e.g., negligence in teaching, advising, and mentoring).

In such contexts, gossip might be a means to minimize reputation damage, but still achieve some level of effective punishment for wrongdoing. Feinberg et al. (2012) suggest that gossip might serve as an effective form of social control, resolving the "social dilemma" (Dawes 1980) generated by the tension between individualism and scientific norms. However, previous research also suggests that gossip has detrimental consequences on organizational culture, in its capacity to weaken trust and morale (Akande and Odewale 1994; Baker and Jones 1996; van Iterson and Clegg 2008). Further, because gossip also has the potential to be inaccurate and misleading (Wilson et al. 2000), we should investigate the extent to which its consumers benefit from its potential warnings. The effect of gossip can also depend on power differentials between gossipers and targets of gossip (Kurland and Pelled 2000), and we need to assess whether prosocial gossip may be more effective in constraining lower-status rather than higher-status transgressors. Feinberg et al.'s (2012) work is also based entirely within a laboratory environment. By examining real-world settings in organizations across diverse scientific fields in 
different countries, we assess the potential that such gossip has as a mechanism of social control in professional life.

\section{$<$ A $>$ Data and Methodology}

This paper draws on data from in-depth interviews $(\mathrm{N}=251)$ with academic scientists in physics departments in the US and UK, and physics and biology departments in India. These data were collected as part of two separate studies.

The first study is a qualitative research project that aims to better understand ethical issues experienced by physicists in the US, UK, and China. For the purposes of this paper, we consider only the US and UK data, since relevant questions were not asked of Chinese scientists - respondents here were especially reluctant to honestly discuss topics that might paint their institutions in a negative light.

We sampled respondents from a sampling frame of elite and non-elite departments, to examine effects of different institutional climates on scientists. ${ }^{2}$ We then contacted a target sample of 17-20 scientists from physics departments in each of these universities for interviews at each department. They were selected using a random stratified sampling method by rank. In total, we interviewed 90 physicists ( 74 men, 16 women) in the US and 81 (72 men, 7 women) in the UK between 2012-2014. Our sample in the US consists of 18 assistant professors, 21 associate professors, and 51 full professors. In the UK we interviewed 23 lecturers, 14 senior lecturers, 16 readers, 26 full professors, and 2 research fellows.

The second study is a mixed-methods study on the role of religion, ethics, gender, and family in the lives of scientists, comprising both nationally representative surveys and qualitative in-depth interviews with physicists and biologists in eight countries. For this paper, we draw only on data from in-depth interviews conducted with scientists in India in 2013-2014, selected on the 
basis of institutional context (elite or non-elite), discipline, gender, and rank. ${ }^{3}$ (Data collection, translation, and analysis are ongoing for other countries at this writing). We conducted a total of 80 in-depth interviews (61 men, 19 women) with Indian physicists and biologists. This sample comprised 23 graduate students, 9 assistant professors, 23 professors, 11 associate professors, and 14 other research staff. For both studies, interviews lasted on average 60 minutes; were conducted either in person, over the phone, or by skype; and were recorded and manually transcribed.

The two studies were not designed with the study of gossip in mind, but with the aim of understanding diverse cultural contexts of science. The countries studied have important differences in science infrastructure and in public understandings of science and scientists. The countries we focus on in this paper-India, the US, and the UK — are very different in terms of scientific infrastructure, productivity, and evaluation systems, meaning that they vary according to factors that may have an impact on understandings of ethics in science. Our studies focus on the disciplines of physics and biology because these fields have distinct varieties and histories of ethical misconduct (Dooley and Kerch 2000; Kirby and Houle 2004; Lerner 2003; Lock 2001). The studies are also designed to examine important differences related to institutional contexts (elite vs. non-elite) and gender. These differences along our various sampling criteria, while important in our broader studies, are not directly relevant to the phenomenon of gossip that we examine in this paper. We found few differences along these axes, and focus the present paper on the types of gossip found in scientific communities, and their perceived causes and consequences. More details about the sampling criteria and studies are available from the authors upon request. 
Gossip was not an initial focus of either of the two studies from which we draw our data. During the course of data collection, however, we noticed that narratives of gossip regularly emerged among our respondents when they described responses to forms of "normal misconduct" they encountered in day-to-day life in their workplaces. We became interested in these narratives and began asking subsequent respondents explicitly about such gossip in their fields of science and its consequences. Thus, data for this paper was collected using an iterative process in which narratives of gossip emerged as an unexpected category from our data and we returned to the field to study them further. Analysis for this paper focuses on interview questions about aspects of the research process that prompt irresponsible conduct; respondents' views about forms of unethical conduct besides fabrication, falsification, and plagiarism (FFP); personal encounters with and responses to ordinary misconduct; and stories of gossip. Data coding began with initial codes based on the existing literature-e.g., misconduct related to FFP vs. non-FFP violations; prosocial functions of gossip; detrimental consequences of gossip; effects of status (De Vries, Anderson, and Martinson 2006; Feinberg et al. 2012; van Iterson and Clegg 2008; Kurland and Pelled 2000)—in addition to inductive categories (e.g., importance of reputation; effective vs. ineffective gossip). We subsequently modified and re-organized categories through a second round of coding, focusing on the different types of gossip scientists engage in and the consequences of their doing so.

The analysis that we present in the following section is not comparative by discipline or gender or elite status of institution —we either had insufficient data across these categories to make such comparisons or found no pertinent differences in narratives of gossip. We do observe some national-cultural differences that we will discuss below, but even here, the similarities outweigh the differences, and our focus is on the common features of the mechanism of gossip 
across diverse scientific communities. We also do not consider here gossip in the form of stories about egregious violators - cases of FFP that have reached public prominence. Rather, our focus is on the kinds of everyday gossip that result when scientists are unable or unwilling to take formal action against a perceived transgressor who engages in less egregious forms of misconduct. In what follows, we describe the two main types of gossip we found across our three national contexts, three kinds of consequences that such gossip can generate, and conclude by discussing implications of our findings.

\section{$<$ A $>$ Results}

\section{$<B>A$ "behind-the-scenes information network"}

The majority of scientists we interviewed in all three countries mentioned the circulation of gossip in their institutions and sub-fields about individuals and groups who violate scientific norms. The forms of prosocial gossip our respondents engage in occur primarily in informal contexts, including casual conversations with department colleagues, or in informal settings at disciplinary conferences. In some cases, it circulates in formal settings as well, such as during decision-making about hiring. One American scientist, a distinguished professor of astrophysics ${ }^{4}$, offered the following image of the gossip that circulates and the consequences it generates:

I think there's a-there's sort of a behind-the-scenes information network. [There are] colleagues who have said, 'Oh, you don't want to work with so-and-so because they're noted for, you know, using your input and expertise and so on and then not crediting you on their publications or their work, so you just want to stay away from them.' And you know, I've known people who I don't work with because I've had that experience with them. And so, you get burned once and you're not too keen to work with those people 
again. And so you know, people's reputation is really important. If you want to continue to collaborate with people - if that's really important to you, you can't treat people that way. I think that—-that's sort of a natural mechanism...

Gossip thus provides scientists with information about the trustworthiness of others in the community. Such gossip is important because, as the above respondent and most others we interviewed insist, one's reputation is a vital asset in the scientific community. With a sullied reputation, one can hardly hope to gain grant funding, get research published in top journals, or secure positions or promotions. Most scientists we interviewed admitted that they took great care to guard their reputations. Reputational concerns motivated many of them to be especially rigorous and careful with their work, and some even prevented their graduate students from presenting at conferences if they considered the students inadequately prepared, because it could diminish the reputation of their labs. Negative gossip about the quality of one's work or about one's potential as a trustworthy colleague and reliable collaborator could very well weaken one's standing in the community, thus devastating a scientist's career. Scientists thus expressed confidence that reputational mechanisms such as gossip served to deter unethical behavior.

The content of such gossip encompasses a variety of behaviors on the part of perceived transgressors that emerged in our interviews: unfairly claiming authorship credit; exploiting students (e.g., imposing unreasonable work expectations, or even abusing students emotionally or physically); being negligent of proper safety procedures (e.g., in dealing with hazardous waste); spending research funding in questionable ways; and publishing papers based on sloppy research or spurious data. Scientists articulate a sense of ambiguity about how to respond to such actions (Johnson and Ecklund 2015), and gossip allows them at the very least to warn their colleagues about perceived transgressors. 
Exposure to such gossip begins early in the socialization process. One biology $\mathrm{PhD}$ student in India ${ }^{5}$ described how from the very beginning, she encountered information about which faculty to work with or avoid, with respect to how they treated students and shared authorship credit: "So, when I joined the lab there were seniors who told me this: 'He's like this. She's like this. She's like that.' So, they tell you." Outside of departments and institutional environments, gossip also circulates in subfields, among colleagues from different institutions and countries who read the same journals and attend the same conferences. Many scientists we spoke to consider such informal gossip as an effective form of "the community policing itself," as one UK physicist ${ }^{6}$ expressed it. While we find some support for such social control, thus reinforcing Feinberg et al.'s (2012) argument about the contribution of "prosocial" gossip to collaboration, we find that such gossip is not always effective.

\section{$<B>$ Types of gossip}

The gossip that circulates among scientists in our sample is of two main types. The first category of gossip mainly has to do with "sloppy" work, which entails violations of Mertonian norms of "organized skepticism"- when scientists rush their work in order to be the first to publish on a topic in a top journal—and "disinterestedness," such as when a scientist's focus is on personal gain rather than scientific achievement (Merton 1973b). The second category comprises pro-social gossip about people one ought to avoid. Such gossip is in response to the violation of norms of "communalism" (when colleagues do not share scientific goods, e.g., by being secretive), "universalism" (when scientists discriminate on bases other than scientific merit), and also infringement of various "inviolable" and "admonitory" norms (Braxton, Proper, and Bayer 2011) that we discuss below.

\section{$<C>$ Gossip about quality of work}


One form of gossip expresses criticism or suspicion of the quality of someone's work. The targets of such comments are usually published papers that are believed to be based on "sloppy" research. As one British Lecturer in Theoretical Physics? told us, "Some of my colleagues are probably more happy to shoot from the hip and publish it quicker than other colleagues." He claimed that he himself, by contrast, would work through his equations more carefully, and "if there's a factor or two missing somewhere, it might destroy a week's work." Some of his colleagues, on the other hand, take short-cuts, "since often you have a hunch what the final result should be." But as a result, "it's very hard to use their work and build on it." This illustrates the potential costs of such misconduct to the generation of knowledge in that it does not provide a solid foundation on which to do future research. So even though they might get published in top journals, their work "has a limited weight" among their peers. "Some wellknown people have a reputation for sloppy work."

A British reader in Physics ${ }^{8}$ similarly told us that some highly successful scientists have reputations for sloppy work: "Yes, some researchers—after a while you know to take their claims with a pinch of salt, in as much as, you know, if you were to reproduce their calculations... you would have to do things slightly better." According to him, this tendency is incentivized by a system that offers the greatest rewards to those who publish on a topic first in the top journals.

The trouble is the people who have this [reputation] - they're the ones who tend to try and... get first to publish, because then they get the higher priority journals. And they tend to publish sloppy work... that's not rigorously done. It's not done to the highest standards. It's not done with the most accurate techniques. But because they get there first, they get the highest publication, highest ranking, and they get the priority. And then 
you come along six months later with the definitive study where you go into much more detail much more rigorously, and the top ranking journals say, "Well, we can't publish that - we already published that." And you say "Yes, but that wasn't a very good paper. We've done it properly and we've dotted all the I's, crossed all the T's. This is the definitive answer." And you end up going to a second rank journal.... The drive to get there first and get the top publication and get the kudos means that they don't do as thorough job as they ought to.

It is not simply individual scientists who develop reputations for sloppy research. A British lecturer in Physics ${ }^{9}$ claimed that a whole subfield he is part of is infamous for this, as demonstrated by the gossip that circulates in his field. But he thinks that sloppy research isn't necessarily unethical or immoral, because "sometimes you can get good results without being rigorous." He too echoes the claim that there are many scientists with bad reputations for sloppy work who can still have a "stellar career," get big grants and high-profile publications. He sees them as "driven by the need for social recognition, not by science." But he doesn't think this is entirely a bad thing. "Maybe their science is not great but they can get money for a good facility which can help other good scientists who cannot master the politics of the field." Many of our respondents expressed the opinion that scientists who were better at networking and impressionmanagement had an edge over those who shied away from self-promotion. As one Indian biology $\mathrm{PhD}$ student ${ }^{10}$ said:

When I see other people who have good networks and are more vocal, who can really popularize their work and can do that, they are much more successful....[T]here are many, many people who are probably not as good scientifically as the shy ones are, but then they are doing much better. 
We are unable to accurately verify any general association between "sloppy" research and well-established networks and reputations. But the cases where such an association exists might prove a challenge to the "self-policing" power of gossip: challengers may not have enough status or reputational capital to seriously undermine transgressors.

\section{$<C>$ Gossip about persons to avoid}

While gossip about sloppy research warns others to exercise suspicion in dealing with particular pieces of research, a second form of gossip warns others to steer clear of certain people. One important locus of such warnings is graduate programs, where students warn one another of professors to avoid.

A biology ABD student in India ${ }^{11}$ argued that one could be an ethical scientist in the sense of avoiding egregious violations such as FFP, but at the same time an "unethical person" in their dealings with students. He claimed that at his university, which is one of the most renowned scientific institutions in the country, scientists who work with "radioactivity and...other neurotoxins" disregard safety procedures when their students are handling these materials: "I know lots of scientists who simply do not care about their students, and the students likewise get this training from their PIs, that it's not important to take care of these radioactive and other harmful stuff. So that I would consider unethical." He went on to give other examples of irresponsible behavior on the part of certain faculty, which he takes pains to communicate to incoming students:

[Y]ou can be an unethical scientist in the sense that you torture your students and you lie to them and then you misguide them at times. You try to, you know, create a rift between two students of yours to create an unhealthy competition.... Or say you favor a person 
particularly from your region and not from the other region.... And that goes on here, pretty much.

A professor of evolutionary biology in India ${ }^{12}$ similarly told us about warnings that circulate among students in his department: "Yes. In fact, many of [the faculty] can be extremely unfair in treating their students. So there are labs which have notoriety. So in some-I think last year a student group posted a notice ... warning incoming students, 'Don't join this lab.'” The common concern expressed in these warnings is mistreatment of students. One ecology $\mathrm{PhD}$ student at another institution ${ }^{13}$ talked about faculty who were "sort of bordering on torturing the students," by which she meant that "the students are expected to be working like ten hours, twelve hours, and they have unreasonable deadlines." The ABD student quoted above gave us an example of a faculty member in his department who was "so, so unethical that [they] bea[t] people up and... abus[e] them.” Apparently this faculty member had a reputation for physically abusing students — hitting them, even "throw[ing] sandals and what not!" The respondent went on to name the faculty member, in the hopes that somebody could "do anything about that." We of course kept their name confidential, but the person turned out to be one of our respondents, and claimed during the interview to have been unfairly branded as a strict, old-fashioned disciplinarian. Nevertheless, as the student admitted, this professor's notoriety did little to hinder their success - not simply in terms of publications and tenure, but even in terms of a continuous inflow of graduate students seeking to work in their lab.

Our findings here resonate with the types of faculty misconduct identified by Braxton, Proper, and Bayer (2011). These authors distinguish between "inviolable norms," the violation of which they argue should receive severe sanctions (e.g., misappropriating students' work, harassing students, suppressing whistle-blowing), and "admonitory norms," the violation of 
which is less severe but is nonetheless harmful to scientific communities (e.g., neglectful teaching, negligent advising, degrading faculty colleagues) (see Braxton, Proper, and Bayer 2011:35, 42-43). The ability to enforce such norms, however, can vary significantly across cultural contexts. In India, we found that students and faculty alike complained about a strongly hierarchical system that made it difficult for lower-status scientists (such as students, postdocs, and even junior faculty) to bring about formal sanctions against high-status transgressors. Our data also suggest a higher degree of tolerance for certain violations (e.g., physical abuse) in India that would see prompt formal sanctions in the west. It is understandable that in such cases, those who are rendered powerless have little recourse but to try to warn other colleagues to steer clear of perpetrators. We argue that these types of relational misconduct in the scientific community should be given as much attention as FFP, since the mistreatment of students may hinder the advancement of science by stifling the development of future scholars.

\section{$<B>$ The fruits of gossip}

What consequences do the above types of gossip have? Our research finds that, on the one hand, for people who consume gossip, it generates three main consequences: it leads them to avoid taking the transgressor's work seriously, to avoid collaboration with the transgressor, and to avoid recommending the transgressor for positions. For the transgressors, on the other hand, gossip has two main consequences: it can either hinder their success or have no effect on it. But as we discuss in this section, even "prosocial gossip" aimed at issuing warnings that preserve a community can generate injustices.

$<C>$ When gossip "works" 
Gossip that raises suspicions about the quality of someone's work can lead people to take the transgressor's work less seriously. We heard such suspicions frequently voiced about certain individuals and groups who published in top journals. As one British professor of Physics ${ }^{14}$ said: If you...in a paper deliberately or even not deliberately mislead the reader, this gets about.... I can think of two scientists whose papers I have read who I thought were actually being deliberately misleading. And this gets about because you'll tell your students, and there'll be gossip among colleagues, and in that way, what these scientists publish is taken with a bigger grain of salt than it might have been.

Gossipers often complained that such gossip circulated when there was insufficient evidence or time to formally contest the study, so the best they could do was to voice their suspicions to colleagues. The above respondent gave us an example of when he came across a published article the conclusions of which he thought were incorrect. He, along with a colleague, published a comment on the paper with calculations to set the matter straight. He continued:

And the response to the comment, I thought, was a little disingenuous. So ... both myself and my colleague thought, "Hmm, maybe this is not a guy we could really trust." Since then, you know, I meet a couple of people at conferences, "What did you think of that paper?" "Oh my God," you know? "Yes, that's what I thought." And that's how it gets around.

A second consequence of such gossip, therefore, is that gossipers avoid collaborating with the transgressor. Many of our respondents told us, like the following British professor of Physics ${ }^{15}$ (from a different university than the above respondent), that gossip deterred them from potential collaborations: "There are a few instances where I would not choose to collaborate with some individuals because of discussions with people I trust.” A British lecturer in plasma 
physics ${ }^{16}$ gave a similar example. Before embarking upon a project with someone who approached him, he asked a senior colleague about that person and was warned that the potential colleague had a reputation for careerism, so decided not to pursue the collaboration.

Such gossip may be more effective in smaller sub-fields, as suggested by an American associate professor of physics ${ }^{17}$, who talked about the gossip that had been circulating in his field about irresponsible conduct on the part of a colleague:

I would say - the consequence has been a sense of distrust of this person. I mean it is such a small community that these types of actions do circulate very quickly. They weren't - you know, they weren't officially reprimanded or they didn't receive a stern note at the project office or at the university or anything like that. But, I think the typical response to these sort of ethical breaches, unless they're extreme, is that people share them...And it just forms your opinion about that group and you would think twice about collaborating with them or sharing with them...Most of those cases have no direct consequence in the sense of, you know, threats to their employment or anything like that. But, most of those cases do have real consequences in the community. Another consequence of such gossip is that these warnings dissuade people from recommending or hiring alleged transgressors. A British lecturer in nanophysics ${ }^{18}$ gave us the following example:

Someone I worked with... in a previous institute, he was a postdoc and he produced a number of publications and I think the general feeling which people discussed was that the work was a bit dodgy, so to speak. And then when that person came to applying for a job here, I rang his supervisor and asked if we should consider him, and he said "No, stay away." 
As a result, the candidate was not considered for that position. Similarly, the first professor $^{19}$ at the beginning of this section told us of a case where he was asked by a committee at a US university if he could write a recommendation for a scientist in his field to be appointed to a named chair at that university. This happened to be the same scientist he mentioned above whose calculations he challenged:

I said, "Well, I couldn't actually do that, and I'm sorry." I didn't say why, but you know, it would have been fairly natural for me to do that considering the field this person worked in. But I knew this person's work very well,... and that's the effect it had.... I imagine this sort of informal mechanism helps to keep the system on the straight and narrow.

Thus, in many cases, gossip certainly seems effective in reinforcing communal norms by informally punishing transgressors. At other times, however, people may inadvertently become victims of inaccurate or misleading gossip.

\section{$<C>$ When gossip goes wrong}

This fragility of gossip is further manifested when people find themselves victims of false gossip, which could either be inadvertent or deliberate. For example, we encountered one respondent in the UK, a Reader in Physics ${ }^{20}$, who in a previous position worked as a research fellow at an institute. He soon learned that a senior colleague had been spreading false rumors about him, which had a negative impact on some of the respondent's collaborations outside that institute: "I experienced people withdrawing from the collaborations. And the name of this person fell, and I was clear that somebody is talking in the background and shared something about the quality of my research, which was obviously not very nice." Apparently this senior 
colleague did not know much about the respondent's research, and was misrepresenting it behind his back "in a completely inappropriate way, in a dismissive way".

Another example came from a physics professor in the $\mathrm{US}^{21}$, who narrated an incident of a colleague who deliberately fabricated gossip about someone whom he saw as a threat, in order to prevent him from being hired:

Basically, this fellow who was from here, he decided that it won't be good to hire this person because he would... take a leading position in this group, and [the incumbent] didn't want to do that. So basically what he did, he wrote a letter to members of the department where he described some incident where this fellow did not behave ethically and so forth. And this was shortly before we had the vote.... I actually put a lot of effort later to clear his name and basically to show that...it [was] fabricated. But it was too late, so he accepted an offer somewhere else, and he's off. So, I think this is a clear example of unethical behavior.

These examples demonstrate that gossip may not simply inhibit unethical behavior, but might also be a channel for it, with the potential to damage one's career when false gossip is believed. However, we found in some cases that gossip has very little effect at all.

\section{$<C>$ When gossip doesn't work}

The power of gossip in the above cases seems contingent on the relative status of gossipers with respect to the transgressor. Many told us about how when they were in relatively junior positions, negative gossip about more senior scientists made little difference to the success of these transgressors.

One assistant professor of particle physics in the $\mathrm{US}^{22}$ recounted how, towards the end of his Ph.D. program, a senior collaborator published a paper to which the respondent had 
significantly contributed, but without giving him any authorship credit. "[E]veryone I've talked to about this believes that I should've definitely been on the paper-I did more than the other person did," he recounted. "I chose not to fight publicly because it would've been I thought much more detrimental to my career to make this person an enemy than to get my name on this paper which wasn't that important." He said he heard similar stories from friends, thus reinforcing a theme we came across in several interviews: scientists in junior positions who are unwilling or unable to formally challenge more powerful and established scientists have little recourse but to warn one another informally, but such gossip has no corrective power over the transgressor's behavior.

An assistant professor of theoretical physics in India ${ }^{23}$ similarly told us about an incident when, as a postdoc, he had some evidence to believe that a senior colleague was falsifying work. He said, "I did make my displeasure known but at that point in time I was only a postdoc, and so I didn't have much say in basically all of these things. I did make my displeasure known but nothing happened.” Another Indian scientist, a professor of molecular biology ${ }^{24}$, complained about how, in spite of gossip and rumors of misconduct, some transgressors at her institution continue to get promoted and remain successful:

Everybody knows it, you know? The experiments were never done, and data's being reported. And sometimes the students from such labs are caught red-handed when they make their work presentations to the whole department. And yet, you know, there'll be no follow-up action. It's all okay. We just don't talk about it. Nobody talks about it. It's extremely common. And such people will get huge funds, because they've got publications to their credit. But everybody sitting in the funding committee will be speaking under their breath about how nothing is verifiable; this guy's data were all 
spurious. Everybody will be talking. You go to a conference, they come and ask you, "Oh, this certain colleague of yours, we heard blah, blah, blah." [change in voice] "Who told you?" [change back in voice] "It was one of my own colleagues who actually supports this person all the time when others question the data, who has told everybody else that everything is false."

When asked why these colleagues support transgressors, she replied, "I haven't understood it. They all don't want to be seen as rocking the boat.... They want to be part of the system and benefit from it, rather than improve it."

Another example from our data of the ineffectiveness of gossip is the previously mentioned case of the professor who had a reputation for beating students. Students in the department took measures to warn others to avoid this professor. As the ABD student ${ }^{25}$ we interviewed told us: "[T]here was posted all over [campus] to prospective students that, 'Please do not join this lab for sure, because your life will be hell!' And you see that thirty four students have left." But these warnings did not seem to prove very effective — new students continue to join every year. According to this respondent, many incoming students thought that "maybe they are special in a way," and that "they will be able to handle [this professor]." He also learned that some of these students disregarded warnings because they suspected them to be a ploy on the part of current students to keep incumbents away—-the professor, after all, was generating successful publications and was a renowned expert in the field. So rather than heed warnings, they preferred to see for themselves.

Another Indian physicist ${ }^{26}$, an associate professor of optics, told us that he was unwilling to informally warn colleagues about transgressors unless he knew "it's not going to, like you know, give a bad name to me." He did not want to be labeled as someone who spreads gossip 
about others, mainly because others might think he has a personal grudge. They might say, "He is commenting on X person, so they don't like each other," he continued. Further, the transgressor may come to know:

And it'll go to that person, and again that person [would say], "Ay, why you commented on me?" Okay? Because, see, many of the things, you may not know the truth. For example, if I'm not in your field, how can I say you did wrong or something? Only thing is, only in the surface I have seen the data. Or maybe, I was told by somebody whom I believed.

In general, most scientists we interviewed talked about gossip as a useful self-policing mechanism since it helps warn people in the community about violators of norms. However, many also express hesitancy_-while admitting that gossip is "common," they are wary of relying on it because it is, as one British quantum physicist ${ }^{27}$ put it, "hard to substantiate."

\section{<A> Discussion}

The scientists we interviewed express confidence in the self-policing mechanisms in the discipline that can deter unethical behavior. We have examined in this paper the forms of gossip that scientists engage in when they are unable or unwilling to take formal action against a perceived transgressor. Our research both supports and contributes to previous research in explaining such reticence or inability.

Often, scientists are not fully confident that an action constitutes an ethical breach; it may be the violation of a norm, but it is not the kind of act against which one can take formal action. There is ambiguity in the meaning of data, for instance, and sometimes the line between "cleaning" and "cooking" data is thin (De Vries, Anderson, and Martinson 2006; Johnson and Ecklund 2015). Verifying an offense also takes a considerable amount of time and effort_even 
to address the suspicions one might harbor while reading a journal article would require investing time that many scientists think could be more fruitfully spent working on their own research. Furthermore, many of these offenses do not fall into the types of misconduct for which there are formal sanctions (FFP). Other forms of misconduct our respondents raise include mistreating students, improper use of funding, and not providing appropriate recognition to collaborators. In these instances, many scientists are unwilling or unable to take formal action. Instead, they voice their suspicions to colleagues in the form of gossip, in the hopes that tarnishing the transgressor's reputation could mitigate their damage.

We find that reputational concerns play a key role in prompting gossip: one might be reluctant to launch a formal complaint if one isn't absolutely certain that they can establish that an offense has been committed. One might be especially wary if the transgressor is in a position of authority. The fear of repercussions for whistleblowing is also a relevant factor here, especially when the transgressor has higher status and more established networks than the gossiper. And even otherwise, nobody wants to be seen as a complainer — some scientists told us this was why they refrained even from publishing critical comments in journals when they spotted errors. Our findings here are consistent with previous research suggesting that scientists are reluctant to speak out against misconduct because they do not want to embarrass offenders, jeopardize their own reputations, or harm the reputations of their institutions, which in turn might negatively affect their funding (Baxton and Bayer 1994). Reputational motivations thus cut both ways: they might inhibit potential transgressors who fear a loss of reputation, but they may also inhibit potential gossipers who fear the personal consequences of spreading gossip.

As a result, in some cases we found scientists expressing a sense of fatalism - that it was "no use" to try to take action of any kind because transgressors were well-established. If the 
transgressor is outside one's institution, it becomes even more challenging to address a grievance because there is no "boss" to even anonymously inform. Other research suggests that such uncertainty of efficacy contributes to scientists' reluctance to speak out (Braxton and Bayer 1994).

Our research also points to the role of cultural context in shaping the content and effectiveness of gossip. Cross-national research suggests that organizational contexts in India have greater "power distance" (i.e., tolerance for unequal distribution of power and acceptance of hierarchy) and "collectivism" (i.e., expectation of loyalty from in-group members) than western countries (Hofstede 2001). Such differences are borne in pervasive complaints we encountered from Indian respondents about strongly hierarchical institutions, favoritism on the part of faculty towards students from their own ethnic groups. In such contexts, it may be more difficult for lower-status individuals to challenge high-status transgressors, and the range of issues against which formal action can be taken would also vary from institutions in the west.

Nevertheless, our research suggests that under certain conditions, gossip might be an effective means of "self-policing" in scientific fields. It can lead scientists to take a transgressor's work less seriously, avoid collaborations with them, or avoid hiring them. One conducive factor to pro-social gossip can be the size of the field: in smaller sub-disciplinary communities, gossip can have more power than in large communities where people may not encounter one another as often. Gossip also seems to enforce social control when the gossiper is of equal or higher status than transgressors. A negative reputation in the eyes of a supervisor, reviewer, or hiring committee member, for instance, can have serious consequences for one's career as a scientist. 
Gossip seems less effective when transgressors already enjoy established networks and reputations. In such cases, it seems more like a relief-valve for those with grievances to let off steam in order to continue persevering in the discipline. Gossip's effectiveness is also diminished when it is inaccurate, or when people abuse gossip channels. Even seeming acts of pro-social gossip could convey inaccurate or unreliable information. Another factor that weakens its effectiveness is disbelief, due to the suspicion that the gossip may be inaccurate or misleading. For instance, in the example we encountered of students in India who disregarded warnings about the physically abusive professor, these students may simply have dismissed these posters as an effort to mislead other students, a ploy to reduce competition. This also suggests that trust among gossipers is an important condition for its effectiveness, and in highly competitive fields, the pervasive low informal trust may inhibit its power. Yet, we also find that in the same institutions, people at times are willing to trust and make decisions based on potentially unreliable information, (see also Sommerfeld et al. 2007; Feinberg et al. 2012), but others seem unwilling to do so without verifying such rumors first-hand. More research is needed to better understand these differences.

While gossip might reinforce bonds and norms among gossipers, it can have adverse consequences on targets of gossip — damaging their relationships and potentially ostracizing them from their communities (Soeters and van Iterson 2002). This effect can be tragic in the case of false gossip. Feinberg et al. (2012:1027) argue that false gossip in such communities should be relatively rare, because "developing a reputation as a false gossiper would likely be quite damaging and would undo any potential benefits one might achieve through spreading such false gossip." But these authors might be neglecting the importance of status differences: being caught spreading false gossip would be detrimental to someone in a junior position, but a senior 
established scientist who wants to keep junior competitors out might very well be able to do so, and even if the gossip were proven false, it would have little effect on their already established reputation.

Established scientists likely also have more extensive social networks, and can "selectively exploit others with less extensive social networks, making it less likely that the transgressor's negative reputation spreads widely" (Feinberg et al. 2012: 1027). Further, as many of our respondents suggested, some transgressors may also be adept at impression management. Given the association between egoist tendencies and strategic impression management (Willer 2012), transgressors may be able to preserve their reputations while continuing to engage in selfserving activities that might be considered irresponsible or unethical with respect to community norms. This suspicion emerged often in our interviews when respondents felt helpless in the face of well-established transgressors, who may be able to inflict punishments on whistleblowers.

A limitation of our approach is that we rely only on interview data and are unable to observe gossip as it happens. We do not, however, see this to be a serious constraint on our argument, since our focus is less on the structure or context of gossip and more on the consequences for participants and targets - knowledge about which can be gained from narratives. The consistency of patterns we find across our cases gives us further confidence in our results. Future research, however, would benefit significantly from participant observation of gossip (e.g., following Hallett, Harger, and Eder et al. [2009]) among scientists to shed further light on the conditions which give rise to such gossip and on its consequences for participants and targets.

\section{$<\mathrm{A}>$ Conclusion}


Ethical misconduct in science is a social problem that impedes scientific progress, undermines public trust in scientific research, increases regulations imposed on researchers (which in turn generates more attempts to find loopholes), and squanders public funding. Our study shows that scientists are concerned with this issue. However, they are not primarily worried about occasional egregious ethical violations such as fabrication, falsification and plagiarism and/or the processes of formal sanctions in response to these types of serious transgressions of scientific norms. Instead they describe their concern with other less serious (and more common) types of ethical violations or "normal misbehavior," also related to the pressures, ambiguities and structures of academic science. These scientists indicate that they use gossip as a strategy for sanctioning these less serious ethically questionable or irresponsible behaviors.

Our findings support recent research, which argues that competition in science has had an impact not only on the frequency of ethical misconduct but also on how scientists themselves experience ambiguity about what counts as unethical behavior (Anderson et al. 2007; Johnson and Ecklund 2015). Gossip about "sloppy work" reflects complaints about scholarship in top journals that is difficult to replicate and build on, and about perverse incentives in scientific institutions that reward networking and impression management over high-quality scientific output. Gossip about people to avoid illustrates how the competitiveness of science can encourage mistreatment of low-status individuals, e.g., by encouraging professors to exploit and mistreat graduate students. While scholars have identified "inviolable" norms when it comes to faculty misconduct (Braxton, Proper, and Bayer 2011), these may go unaddressed except through gossip, which may have little impact on high-status perpetrators. Competitive pressures can thus 
lead scientists to lose sight of broader ethical concerns to the detriment of future generations of scientists.

We thus echo De Vries, Anderson, and Martinson's (2006) argument that policymakers' limited focus on egregious misconduct overlooks many important ways in which scientists face ethical challenges and make compromises in order to navigate structural constraints. Challenging misconduct formally is easier for those in higher-status positions (Braxton and Bayer 1994), and our research suggests that people in lower-status positions relative to transgressors may often have little recourse to means other than gossip.

Studying gossip also affords new insights into how ethical norms are informally transmitted, sustained, and violated in professional communities. Unethical behavior plays a vital role in social life because it affirms norms and defines moral boundaries (Durkheim 1982 [1895]). A robust literature in the sociology of professions consistently shows that embracing the norms of a profession involves more than the formal acquisition of knowledge, but depends largely on informal and interactional processes in the socialization process (Becker et al. 1961; Merton, Reader, and Kendall 1957). Junior scientists do not simply internalize ethical norms and consistently enact them, as some of the classic socialization literature suggests (Merton, Reader, and Kendall 1957); rather, their behaviors are shaped by contextual norms of socially desirable behavior that may run counter to the formal principles they espouse (Haas and Shaffir 1987; Vaidyanathan 2015). As De Vries, Anderson, and Martinson (2006) argue, such "normal misbehavior" is common in science and plays "a useful and irreplaceable role" in enabling scientists to deal with uncertainties and ambiguities in their environment. Nevertheless, these types of ethically questionable behaviors provide cause for concern because they can contribute 
to institutional cultures that cultivate unethical behavior, and constitute what scientists themselves consider impediments to scientific integrity.

Our research also contributes to existing research on gossip in a number of ways. We extend the work of Feinberg et al. (2012) on "pro-social gossip" outside laboratory settings to examine its role in day-to-day workplace contexts in scientific communities. We identify three ways in which such gossip can be effective as a social sanction-by leading colleagues to take a transgressor's work less seriously, to avoid collaborating with them, or to avoid hiring them. Such examples that abound among our respondents leave many of them with a sense of confidence in the self-policing capacity of the discipline due to the threat of a tarnished reputation. However, our findings on the limitations of such pro-social gossip suggest that this confidence may be misplaced. While such gossip may impose sanctions on transgressors, because transgressors may remain unaware of the gossip or the causes of the sanctions, such gossip may not lead to corrections that bring transgressors back in line. Scholars of pro-social gossip have neglected how it can cause harmful consequences when it is inaccurate or misleading (Wilson et al. 2000), or the role of status and power differentials between gossipers and targets (Kurland and Pelled 2000). Our findings suggest that status differences are a crucial factor in conditioning the effectiveness of pro-social gossip. Our work illustrates how reputational concerns can both prompt and deter people from engaging in gossip, and future research could examine this ambivalence further. Our work also points to the importance of cultural differences in shaping the effectiveness of pro-social gossip. Future research would benefit from more systematically exploring such differences along with factors such as gender and status based on position or "rank" in academic hierarchies. We would also benefit from further research on other types of informal responses to misconduct in science and from 
investigating the importance of these ethically questionable behaviors and sanctioning mechanisms in academic contexts outside of the natural sciences.

Under the conditions we have identified, gossip can play an important role in sustaining, transmitting, and informally enforcing scientific norms. While its power may be limited by status differentials and verifiability concerns, serious attention to the contents of such gossip might alert the academic community to violations of ethical standards in research that continue to go undetected. Such insights could consequently have significant implications for enhancing ethical climates in academic cultures by improving ethics education, policies, and sanctioning procedures.

\section{$<$ A $>$ References}

Akande, Adebowale and Funmilayo Odewale. 1994. "One More Time-How to Stop Company Rumours.” Leadership and Organization Development Journal 15(4):27-30.

Anderson, Melissa S., Karen S. Louis, and Jason Earle. 1994. "Disciplinary and Departmental Effects on Observations of Faculty and Graduate Student Misconduct" Journal of Higher Education 65(3):331-350.

Anderson, Melissa S., Emily A. Ronning, Raymond De Vries, and Brian C. Martinson. 2007. “The Perverse Effects of Competition on Scientists Work and Relationships" Science and Engineering Ethics 13:437-461.

Baker, Jane S., and Merrill A. Jones. 1996. “The Poison Grapevine: How Destructive are Gossip and Rumor in the Workplace." Human Resource Development Quarterly 7(1):75-86.

Becker, Howard S., Blanche Geer, Everett C. Hughes, and Anselm L. Strauss. 1961. Boys in White: Student Culture in Medical School. Transaction Publishers. 
Ben-Ze'ev, Aaron. 1994. “The Vindication of Gossip.” Pp. 11-24 In Good gossip edited by Robert F. Goodman and Aaron Ben-Ze'ev. Lawrence: University Press of Kansas.

Bird, Stephanie J. 2006. "Research Ethics, Research Integrity and the Responsible Conduct of Research." Science and Engineering Ethics 12(3):411-412.

Blumenthal, David, Eric G. Campbell, Manjusha Gokhale, Recai Yucel, Brian Clarridge, Stephen Hilgartner, and Neil A. Holtzman. 2006. "Data Withholding in Genetics and Other Life Sciences: Prevalences and Predictors.” Academic Medicine 81(2):137-145. Braxton, John M. and Alan E. Bayer. 1994. "Perceptions of Research Misconduct and an Analysis of Their Correlates." The Journal of Higher Education 65(3):351-372.

Braxton, John M., Eve Proper, and Alan E. Bayer. 2011. Professors Behaving Badly: Faculty Misconduct in Graduate Education. Baltimore: John Hopkins University Press.

Check, Erika. 2002. "Scientific Misconduct: Sitting in Judgment." Nature 419:332-333.

Davis, Mark S., Michelle Riske-Morris, and Sebastian R. Diaz. 2007. “Causal Factors Implicated in Research Misconduct: Evidence from ORI Case Files." Science and Engineering Ethics 13(4):395-414.

Dawes, Robyn M. 1980. “Social dilemmas.” Annual Review of Psychology 31:169-193.

Dawson, Jim. 2003. "New APS Ethics Guidelines Address Research Misconduct and Professional Responsibilities." Physics Today 56(March):20-22.

De Vries, Raymond, Melissa S. Anderson, and Brian C. Martinson. 2006. "Normal Misbehavior: Scientists Talk about the Ethics of Research." Journal of Empirical Research on Human Research Ethics 1(1):43-50.

Dooley, James J. and Helen M. Kerch. 2000. "Evolving Research Misconduct Policies and their Significance for Physical Scientists." Science and Engineering Ethics 6(1):109-21. 
Dunbar, Robin I.M. 2004. “Gossip in Evolutionary Perspective.” Review of General Psychology 8(2):100-110.

Durkheim, Emile. 1982 [1895]. The Rules of the Sociological Method. New York: Free Press.

Eder, Donna, and Janet Lynne Enke. 1991. "The Structure of Gossip: Opportunities and Constraints on Collective Expression Among Adolescents.” American Sociological Review 56(4):494-508.

Fanelli, Daniele. 2009. "How Many Scientists Fabricate and Falsify Research? A Systematic Review and Meta-Analysis of Survey Data." PLoS One 4(5):5738. doi: 10.1371/journal.pone.0005738.

Feinberg, Matthew, Robb Willer, Jennifer Stellar, and Dacher Keltner. 2012. "The virtues of gossip: reputational information sharing as prosocial behavior. " Journal of Personality and Social Psychology 102(5):1015-1030.

Foster, Eric K. 2004. "Research on Gossip: Taxonomy, Methods and Future Directions." Review of General Psychology, 8(2):78-99.

Freeman, Richard, Eric Weinstein, Elizabeth Marincola, Janet Rosenbaum, and Frank Solomon. 2001. "Competition and Careers in Biosciences." Science 294(5550):2293-2294.

Gabriel, Yiannis. 1995. "The Unmanaged Organization: Stories, Fantasies and Subjectivity." Organization Studies 16(3):477-501.

Haas, Jack, and William Shaffir. 1987. Becoming doctors: The adoption of a cloak of competence. Greenwich, Conn.: JAI Press.

Hackett, Edward J. 1994. A social control perspective on scientific misconduct. The Journal of Higher Education 65(3):242-260. 
Hallett, Tim, Brent Harger, and Donna Eder. 2009. “Gossip at work: Unsanctioned Evaluative Talk in Formal School Meetings." Journal of Contemporary Ethnography 38(5):584-618. Hofstede, Geert. 2001. Culture's consequences: Comparing values, behaviors, institutions and organizations across nations. Thousand Oaks, CA: Sage.

Johnson, David R., and Elaine Howard Ecklund. 2015. "Ethical ambiguity in science." Science and Engineering Ethics, forthcoming in print, published online: DOI: 10.1007/s11948015-9682-9.

Juliano, Rudolph L. 2003. “A shortage of Ph.D.s?” Science 301:763.

Kakuk, Peter. 2009. "The Legacy of the Hwang Case: Research Misconduct in the Biosciences." Science and Engineering Ethics 15(4):545-562.

Kennedy, Donald, Crispin Taylor, Kirstie Urquhart, and Jim Austin. 2004. "Supply Without Demand." Science 303:1105.

Kirby, Kate and Frances A. Houle. 2004. "Ethics and the Welfare of the Physics Profession" Physics Today 57(11):42-46.

Kniffin, Kevin M., and David S. Wilson. 2005. "Utilities of gossip across organizational levels: Multilevel selection, free-riders, and teams." Human Nature 16(3):278-292.

Kurland, Nancy B. and Lisa H. Pelled. 2000. "Passing the Word: Toward a Model of Gossip and Power in the Workplace.” Academy of Management Review 25(2):428-438.

Lerner, Eric J. 2003. “Fraud Shows Peer Review Flaws” Industrial Physicist 8(6):12-17.

Lock, Stephen. 2001. "Research Misconduct 1974-1990: An Imperfect History" in Fraud and Misconduct in Biomedical Research edited by Stephen Lock and Frank Wells. London: BMJ Books. 
Martinson Brian C., Melissa S. Anderson, and Raymond De Vries. 2006. "Scientists' Perceptions of Organizational Justice and Self- Reported Misbehaviors." Journal of Empirical Research on Human Research Ethics 1(1):51-66.

Merton, Robert K., George G. Reader, and Patricia Kendall. 1957. The Student Physician: Introductory Studies in the Sociology of Medical Education. Harvard University Press.

Merton, Robert K. 1973a. "The Normative Structure of Science.” In The Sociology of Science: Theoretical and Empirical Investigations. University of Chicago Press.

Merton, Robert K. 1973b. "Priorities in Scientific Discovery." In The Sociology of Science: Theoretical and Empirical Investigations. University of Chicago Press.

Michelson, Grant, Ad van Iterson, and Kathryn Waddington. 2010. "Gossip in Organizations: Contexts, Consequences, and Controversies." Group \& Organization Management 35(4):371-390

Noon, Mike and Rick Delbridge. 1993. "News From Behind my Hand: Gossip in Organizations." Organization Studies 14(1):23-36.

Office of Research Integrity (ORI). 2011. Definition of Research Misconduct. Accessed online at http://ori.hhs.gov/definition-misconduct

Ogasawara, Yuko. 1998. Office Ladies and Salaried Men: Power, Gender, and Work in Japanese Companies. Berkeley: University of California Press.

Paine, Robert. 1967. "What is Gossip About? An Alternate Hypothesis." Man 2(2):278-285.

Reich, Eugenie S. 2009. Plastic Fantastic: How the Biggest Fraud in Physics Shook the Scientific World. Palgrave Macmillan.

Rosnow, Ralph L. 1977. “Gossip and Marketplace Psychology.” Journal of Communication 27(1):158-163. 
Soeters, Joseph and Ad van Iterson. 2002. "Blame and Praise Gossip in Organizations:

Established, Outsiders and the Civilising Process.” Pp. 25-40 in The Civilised Organization: Norbert Elias and the Future of Organization Studies edited by Ad van Iterson, Willem Mastenbroek, Tim Newton, and Dennis Smith. Philadelphia, PA: John Benjamins.

Sommerfeld, Ralf D., Hans-Jürgen Krambeck, Dirk Semmann, and Manfred Milinski. 2007.

"Gossip as an alternative for direct observation in games of indirect reciprocity." PNAS:

Proceedings of the National Academy of Sciences 104(44):17435-17440.

Stern, Andrew M., Arturo Casadevall, R. Grant Steen, and Ferric C. Fang. 2014. "Financial Costs and Personal Consequences of Research Misconduct Resulting in Retracted Publications." eLife 3:e02956.

Teitelbaum, Michael S. 2003. "Do We Need More Scientists?” The Public Interest 153(Fall):4053.

van Iterson, Ad and Stewart R. Clegg. 2008. "The Politics of Gossip and Denial in Interorganizational Relations." Human Relations 61(8):1117-1137.

Vaidyanathan, Brandon. 2015. "Professional Socialization in Medicine." The American Medical Association Journal of Ethics 17(2):160-166.

Willer, Robb. 2012. “Is Generosity Sincere or Strategic? Altruism versus Status-Seeking in Prosocial Behavior." Society for Personality and Social Psychology Annual Meetings. San Diego. January 2012.

Wilson, David S., Carolyn Wilczynski, Alexandra Wells, and Laura Weiser. 2000. “Gossip and Other Aspects of Language as Group-Level Adaptations.” Pp. 347-365 in The Evolution of Cognition edited by Cecilia Heyes and Ludwig Huber. Cambridge, MA: MIT Press 
Ziman, John. 2000. Real Science: What it is, and What it Means. Cambridge University Press. Zimmer, Carl. 2012. "A Sharp Rise in Retractions Prompts Calls for Reform.” New York Times. April 162012.

\section{$<$ A $>$ Notes}

${ }^{1}$ We thank an anonymous reviewer for this observation.

${ }^{2}$ Because we neither expected nor observed differences by elite status to have any bearing on the mechanisms of gossip, we footnote the details of this aspect of our sampling methodology. To determine elite status in the US, we used the National Research Council (NRC) rankings. In the UK, we first used Web of Science (WoS) to create a sampling frame of all university physics departments which had published an article between 2001-2011 and then categorized these departments into elite and non-elite by triangulating publication levels (as indicated by WoS), rankings in the UK Research Assessment Exercise, and consultations with UK scientists. On these bases, we selected nine US universities (4 elite and 5 non-elite) and 7 UK universities (4 elite and 3 non-elite).

${ }^{3}$ Our sampling frame of universities and research institutions in India was constructed using Web of Science, and comprised the institutions that had contributed at least one publication between 2001-2011 to journals in physics and biology. We determined elite versus non-elite status by combining research productivity (as indicated by WoS) and consultation with Indian scientists. In the second stage of sampling, we constructed a representative sampling frame of all scientists in the biology and physics departments of each university. We surveyed this sample, and drew our interview sub-sample from survey respondents who agreed to be interviewed.

${ }^{4}$ US86, female, physics, professor 
${ }^{5}$ IND10, male, biology, graduate student

${ }^{6}$ UK30, male, physics, professor

${ }^{7}$ UK33, male, physics, senior lecturer

${ }^{8}$ UK43, male, physics, reader

${ }^{9}$ UK76, female, physics, senior lecturer

${ }^{10}$ IND11, female, biology, graduate student

${ }^{11}$ IND10, male, biology, graduate student

${ }^{12}$ IND05, male, biology, professor

${ }^{13}$ IND01, female, biology, graduate student

${ }^{14}$ UK30, male, physics, professor

${ }^{15}$ UK50, male, physics, professor

${ }^{16}$ UK41, male, physics, lecturer

${ }^{17}$ US89, male, physics, associate professor

${ }^{18}$ UK77, male, physics, lecturer

${ }^{19}$ UK30, male, physics, professor

${ }^{20}$ UK42, male, physics, reader

${ }^{21}$ US05, male, physics, professor

${ }^{22}$ US67, male, physics, assistant professor

${ }^{23}$ IND07, male, physics, assistant professor

${ }^{24}$ IND08, female, biology, professor

${ }^{25}$ IND10, male, biology, graduate student

${ }^{26}$ IND37, male, physics, associate professor

${ }^{27}$ UK75, male, physics, senior lecturer 